\title{
Diagnostic laparoscopy in isolated torison of hydrosalpinx: a likely cure for an unlikely disorder
}

\author{
Manu Priya*, Modhusmita Chetia, Asha Sharma, Mona Verma
}

Department of Obstetrics and Gynecology, St. Stephens Hospital, New Delhi, India

Received: 11 January 2018

Accepted: 10 February 2018

\section{*Correspondence:}

Dr. Manu Priya,

E-mail: madhavanranjit@gmail.com

Copyright: (C) the author(s), publisher and licensee Medip Academy. This is an open-access article distributed under the terms of the Creative Commons Attribution Non-Commercial License, which permits unrestricted non-commercial use, distribution, and reproduction in any medium, provided the original work is properly cited.

\begin{abstract}
Isolated torsion of fallopian tubes is a rare cause of acute abdomen. It is a diagnosis that is often reached after much delay. This is primarily because it has no pathognomonic clinical, radiological or laboratory signs. In such cases, it is advisable to have a low threshold for diagnostic laparoscopy. We managed a middle-aged lady with acute abdomen and after initial tests were inconclusive, we proceeded to diagnostic laparoscopy without much delay and found a twisted right hydrosalpinx. We performed a right salpingectomy as her family was complete. The fallopian tube and ovary usually act as a unit and an isolated torsion of the fallopian tube is a rare occurrence with few tell-tale sign. After cross sectional imaging, we can be fairly certain of an adnexal pathology. A delay in making a diagnosis can lead to catastrophic consequences in such conditions. An early laparoscopy can be both diagnostic and therapeutic in these cases.
\end{abstract}

Keywords: Adnexa, Fallopian tube, Hydrosalpinx, Laparoscopy, Ovary, Torsion

\section{INTRODUCTION}

Isolated torsion of fallopian tubes is an uncommon cause of acute lower abdominal pain. It has an incidence of 1 in 1.5 million women. ${ }^{1}$ It often presents as a diagnostic dilemma since there are no pathognomonic clinical, laboratory or radiological features. ${ }^{2-7}$ Since the advent of laparoscopy, diagnostic laparoscopy has been a handy tool in the work up of abdominal pain.

We treated a 38-year-old lady, who presented with severe abdominal pain and despite the use of cross sectional imaging; a definite diagnosis remained elusive until a diagnostic laparoscopy was performed.

We found a twisted right hydrosalpinx and performed laparoscopic right salpingectomy. In patients with rare diseases, diagnosis and management are often reached after much delay. The use of laparoscopy allowed a timely decision to be made in our case and helped in appropriate management of this patient.

\section{CASE REPORT}

A 38-year-old lady, mother of 4 children, with one abortion and one $\mathrm{C}$-section, tubectomised 4 years ago, presented to us with pain in the lower abdomen for 8 hours, associated with nausea and vomiting. There was no discharge or bleed PV. Her last menstrual period was 40 days ago but prior to that menstrual cycle was regular with normal duration and flow. She was afebrile, her vitals were stable and there was no tachycardia. On palpation of abdomen, there was no tenderness or any other significant finding except central obesity. On per vaginal examination, exact size of the uterus could not be made out; it was retroverted with no forniceal tenderness and a vague mass was palpable on the right side of the pelvis. Complete blood count, renal function tests, 
electrolytes and $\mathrm{Ca} 125$ were normal. Considering the overdue of menses, urine pregnancy test was done and found to be negative. Ultrasound of the abdomen and pelvis revealed a normal sized uterus with endometrial thickness of $5 \mathrm{~mm}$ and right ovarian cystic mass measuring $6.6 \times 8.4 \mathrm{~cm}$ in size with no increase in peripheral vascularity (Figure 1).

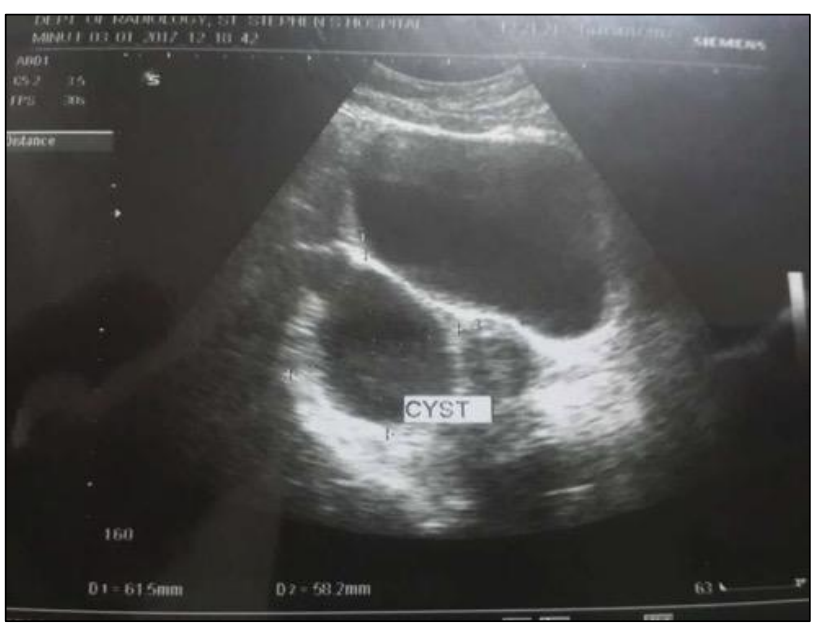

Figure 1: Ultrasonographic examination showing a cystic lesion of the adnexa.

Magnetic resonance imaging (MRI) was done with contrast to rule out torsion. MRI was suggestive of right sided hydrosalpinx measuring $6.6 \times 7 \mathrm{~cm}$ in size. No free fluid was found, and no other significant abnormality was found. Since her pain did not subside despite intravenous analgesics and antibiotics, suspicion of Pelvic Inflammatory Disease (PID) or adnexal torsion was made. After taking informed written consent, patient was shifted for diagnostic laparoscopy without any further delay.

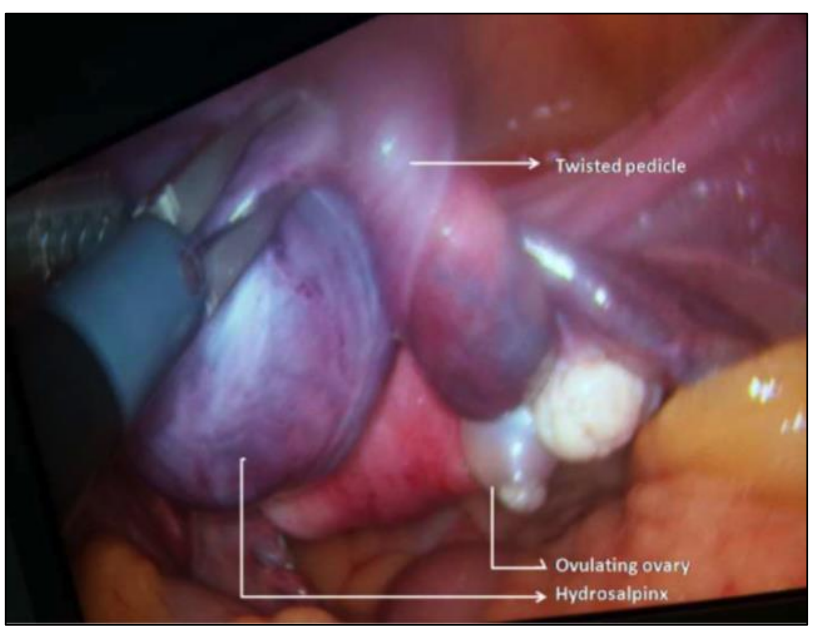

Figure 2: Intraoperative picture showing twisted pedicles and ovulating ovaries.

On diagnostic laparoscopy, we found mass of $6 \times 9 \mathrm{~cm}$ in the right adnexa with three twists at the base of adnexal region (Figure 2). Fimbrial end of the right fallopian tube was traced, which was occluded with flimsy adhesions (Figure 2) and hence a diagnosis of right twisted hydrosalpinx was made. The right ovary was found to be ovulating (Figure 2). Left ovary and fallopian tube was normal. We untwisted the hydrosalpinx and aspirated clear fluid from it to decompress the mass. The mass was excised with the help of bipolar electrocautery and scissors. Homoeostasis was ensured. Patient had an uneventful post-operative recovery and was discharged on post op day 4 in a stable and pain free state. Histopathological examination was indicative of hydrosalpinx of the fallopian tube.

\section{DISCUSSION}

The fallopian tube and ovary act as a unit and isolated torsion of just the fallopian tube is an unlikely occurrence. $^{2-7}$ It was first described by Bland-Sutton in 1980s and continues to torment patients and physicians alike by being difficult to diagnose. ${ }^{8}$

As in the present case, it is more likely to occur in premenopausal women., ${ }^{1,2}$ Anatomical factors such as hydrosalpinx as found in our patient may predispose the fallopian tube to torsion. ${ }^{2}$ However not all hydrosalpinx lead to torsion as they are preceded by Pelvic Inflammatory Disease (PID) and PID leads to formation of adhesions. Adhesions restrict the mobility of fallopian tubes. In our patient, adhesions were few and past history was not suggestive of PID. Other predisposing factors include prior surgery and tubal ligation, which were present in our patient. ${ }^{1,2}$ Our patient was affected on the right side. Torsion is less common on the left as the mobility of the fallopian tube is restricted by sigmoid colon. ${ }^{1}$

The presentation of torsion of the fallopian tube is nonspecific. $^{1-7}$ It is difficult to reach a diagnosis of torsion of hydrosalpinx by clinical features alone or laboratory values, which are nonspecific. ${ }^{1-7}$ Ultrasonography (USG) shows a cyst separate from the ovary but the large size of hydrosalpinx may obscure the ovary and as in our case, it is difficult to differentiate the two on USG. ${ }^{2-3,9}$

Retained blood flow to the ovary favors isolated torsion of the fallopian tube. Despite this, making a pre-operative diagnosis of isolated torsion is unlikely. Cross sectional imaging would also be unhelpful in making a definite diagnosis. ${ }^{9,10}$

After all these investigations in a patient with isolated fallopian tube torsion, we can be fairly certain that an adnexal pathology is present even if a definite diagnosis has not been made. At this stage, differential diagnosis included adnexal torsion, ectopic pregnancy, PID and torsion of sub-serous degenerative leiomyoma. Surgical exploration was the next step, but exploratory laparotomy 
would be a morbid procedure. So, we decided to proceed with diagnostic laparoscopy.

\section{CONCLUSION}

The advent of laparoscopy has provided us with a valuable tool in the management of pain abdomen. It provides a definitive and minimally invasive mode of diagnosis, which can also be therapeutic as in our case. If the affected adnexa is gangrenous or if family is complete, it should be completely resected. Since our patient's family was already complete, we decided to go ahead with right salpingectomy.

\section{ACKNOWLEDGMENTS}

Authors acknowledge the role of Dr. Kumar Madhavan in preparation of the manuscript.

Funding: No funding sources

Conflict of interest: None declared

Ethical approval: Not required

\section{REFERENCES}

1. Augustin G. (Isolated) Torsion of the fallopian tube in acute abdomen during pregnancy. Springer International Publishing; 2014:461-464.

2. Toyoshima M, Mori H, Kudo K, Yodogawa Y, Sato $\mathrm{K}$, Kudo $\mathrm{T}$, et al. Isolated torsion of the fallopian tube in a menopausal woman and a pre-pubertal girl: two case reports. J Med Case Rep. 2015;9(1):1.

3. Dey M, Kumar R. Isolated torsion of hydrosalpinx. Med J Armed Forces India. 2013;69(2):178.

4. Kardakis S, Barranca A, Vitelli A, Amore I, Trento F, Caccia G. Isolated fallopian tube torsion. Case Rep Obstet Gynecol. 2013;2013.

5. Hansen $\mathrm{OH}$. Isolated torsion of the fallopian tube. Acta Obstetricia et Gynecologica Scandinavica. 1970;49(1):3-6.

6. Bernardus RE, Van der Slikke JW, Roex AM, Dijkhuizen GH, Stolk JG. Torsion of the fallopian tube: some considerations on its etiology. Obstet Gynecol. 1984;64(5):675-8.

7. Rajaram S, Bhaskaran S, Mehta S. Isolated Fallopian tube torsion in adolescents. Case Rep Obstet Gynecol. 2013;2013.

8. Bland-Sutton T. Salpingitis and some of its effects. Lancet. 1890;2:146-8.

9. Jain, Nidhi. Adnexal torsion-symptoms, diagnosis and management: a review of literature. IJRCOG. 2017;5(5):1276-84.

10. Thakral, Anuj. MRI diagnosis of tubal torsion: the whirlpool sign. IJRCOG. 2016;5(1):237-9,

Cite this article as: Priya M, Chetia M, Sharma A, Verma M. Diagnostic laparoscopy in isolated torison of hydrosalpinx: a likely cure for an unlikely disorder. Int J Reprod Contracept Obstet Gynecol 2018;7:1228-30. 